\title{
The Role of Morphology in the Process of Language Acquisition and Learning
}

\author{
Joaquín A. Domínguez \\ Universidad Autónoma de Barcelona
}

\begin{abstract}
Morphology is attracting more and more the interest of linguists. No complete theory of language can develop without a well established theory of word formation. There are many unsolved problems, however, which make any morphological theory a weak theory, badly nceding evidence based solutions, some of them crucial to the theory; these are for example, productivity, meaning, constraints, and so on. We are also concerned with the acquisition/learning of the rules of word formation. In this respect we draw out conclusions from other authors' cvidence and from our own.
\end{abstract}

\section{Introduction}

In the structuralist period linguistics became a scientific discipline. During this period linguistics succeeded among other things in the identification and analysis of the units of language from the simplest, the phoneme, to the most complex, the sentence, including the intermediate ones such as the morpheme and the word. But they did not go any further. One important flaw in this treatment was the fact that they did not attempt to deal with the creative aspect of language use, with the fact that any speaker can «make infinite use of finite means» (Chomsky Aspects 8).

For the generativists language is not static, complete, but a dynamic, always developing phenomenon, a process of the mind of the speaker. They have as a goal the description of this linguistic capacity of the human brain. Chomsky says:

It is necessary to reject this [Saussure's] concept of langue as merely a systematic inventory of items and to return rather to the Humboldtian conception of underlying competence as a system of generative process. (Aspects 4)

Generativists attempt to uncover the hidden linguistic competence of the speakers of a language, which are able to produce an infinite number of sentences from very limited contact with the language. 
We cannot afford to look into the human brain in order to watch how it processes language. To solve this problem linguistics build hypotheses which have to be contrasted with new linguistic data in order to verify their appropriate workirg. In this way we are able to build the theory of a particular language, its grammar. This grammar attempts to describe the «linguistic competence of the fluent native speaker of the language» (Radford 2).

For the grammar of a particular language to be descriptively adequate it must be based on more general principles, in universal grammar, i.e. a series of general tendencies observed in all natural languages.

A very important goal of linguistic science is the determination of the rank of morphology in the grammar of a particular language and in universal grammar.

American structuralism focused its attention on units smaller than the word and was not interested in word formation, maybe because of the vagueness of the term «word.» For generative-transformational grammar the unit of linguistic description was the sentence, and all its efforts were directed to its study. But the first applied study of the theory was some research on the generative rules of compound words in English by R. B. Lees. Lees considered word formation the result of operations of the syntactic rules. Morphology was then taken as a subcomponent of syntax.

Word formation started to attract the attention of linguists as a consequence of Chomsky's publication in 1970, «Remarks on Nominalization,» which caused one of the most important divisions in the linguistic field among the supporters of lexical principles and those of the transformational ones.

Nowadays morphology is considered an autonomus component on the same footing as syntax and semantics. Morphological rules have formal characteristics and principles of their own, and their study has led linguists to discover that the morphological subcomponent is rule-governed and its rules have more generality than they were originally accorded.

Words appear in consulting dictionaries alphabetically ordered. Affixes are part of these lists. Word formation rules operate on bases (roots in Spanish, words in English) and produce changes, visible or invisible, whose result is a new complex or compound unit.

Although some consensus has been reached among linguists on some morpho'ogical topics, many problems still remain to be solved, as for example, the configuration of the morphological subcomponent, the relation of the lexical component to the other components of the grammar, the effects of meaning on word formation rules, the syntactic and phonetic constraints, etc.

Closely related to this is the productivity of morphological rules. The variety of patterns and the lack of productivity of many of them has provoked the apathy of linguists for morphology. But there are also some linguists who consider morphology as productive as syntax (see Di Sciullo and Williams 7-10).

The most important problem of morphological rules is, no doubt, their lack of generality. The positive and negative conditions on the rules formulated by linguists considerably reduce their generative capacit to such a point that they cause us to question ourselves about what a rule is. If a hypothesis is not general enough so as to allow some degree of predictability, it is not a rule; it rather becomes a brief statement or enumeration of the bases on which the rules operate. 
Morphology contains the rules which allow the speaker to increase his/her linguistic competence through their application. But it only contains those regular processes which present the working of the system as a coherent and non arbitrary device.

Linguists, psychologists and teachers are interested in morphology because they expect it to be a good means to find out more about the strategies the speakers use in order to increase their lexical capacity. In some circumstances in their daily life speakers have to coin new words which they use to express their thoughts. Word formation ex nihilo is merely episodic in language, but the formation of new lexical units using the resources of language, its morphology, is taking place continually. We try to capture the underlying knowledge which allows native speakers to form new lexical units by using such language devices as derivation and composition.

The knowledge of morphology is necessary in order to know the way the human brain works and processes language. It will help to produce new alternatives to learn languages, which are more economical in time and effort than those we are using now and it will permit its application to artificial intelligence.

\section{Productivity}

The grammar of the language is usually defined as the formal representation of the knowledge the speakers of the language have of their language. It accounts for the capacity the speakers have to produce an infinite number of sentences, many of them new, and to interpret all those which reach their ears or eyes even if it is the first time they come across them.

If this is true of the grammar it must also be true of morphology, one of its components. It is obvious, then, that morphology must account for the morphological competence of the speakers. It must be a mirror of the intuitions they have on the formation, interpretation and recognition of the lexical units of their language. It explains why a native English speaker knows that unspeakable is a word of his language but ablespeakun is not, and a native Spanish speaker will say that inenarrable is Spanish but ableinenarr is not.

Now it is necessary to clarify the structure of the lexical component and the way we hypothesize that it works. In order to work the way it does it seems that it must contain a dictionary with the lexical aspects the speaker has to internalize; those rules which allow the speaker to make generalizations, to form hypotheses: derivation and composition; other rules which are not productive any more, but which allow the learner to explain the internal structure of existing compounds; those general principles which articulate the rules of word formation, and, finally, the rules of inflection. Morphology must determine the boundaries of morphological regularity in a language; in order to do that it must make a distinction between possible and non-possible constructions.

Above we said that the productivity of word formation rules is one of the most controversial topics in morphology. They do not question the productivity of some rules but word formation in general (see Chomsky «Remarks» 184-215). In linguistics we say that a process is productive when it is used synchronically to make up new linguistic units, and not productive when it does not permit that. 
The rules of word formation constitute a coherent whole like the rules for the formation of phrases, but the two classes of rules are different. When we say that word formation rules are productive we mean that native speakers can produce and interpret new words, and in this sense the productivity of word formation rules and the productivity of the rules for the formation of phrases are identical.

The number of phrases in a language is infinite. It is said that in syntax we cannot speak of the longest phrase; there will always be categories which can be added to the last one. This property is due to the recursive capacity of some rules which introduce syntactic categories. We assume that the structures generated by recursive rules are grammatical, but not necessarily acceptable for the native speakers because those have short range memory.

In syntax we find many patterns to illustrate this process; among others we can mention:

- the coordination of constituents which can apply endlessly: Peter and Sue and Ann and ...

- relative clauses: This is the dog that chased the cat that chased the rat that ate the cheese that ...

- verbal complementation: John says that Bob says that Sue says that Ann says ... that Mary is engaged

Anyone of these rules may also form recursive structures in Spanish.

So there are rules in morphology too. «In the Germanic languages, at least, there is no such thing as the longest compound» (Bauer 66). «... we might then propose that the grammar permit the single concatenation of any two nouns as a third nominal. This would then have the required convenient recursive property needed to account for such indefinitely extendable series as: typewriter repair, repair shop, typewriter repair shop, typewriter repair shop supplies, etc.» (Lees 117). Bauer writes the following example: «His great-great-great-great-great-great-great-great-great-greatgreat-great-great-great-great-great-grandfather was killed in a Viking raid on Holy Island» (67).

Romance languages use word composition in much less degree than Germanic languages do, but they contain productive word formation rules which can compete in productivity with the Germanic ones. In Spanish the people from the country speak about segadora-trilladora, cosechadora-empacadora, and it is possible to find a segadora-trilladora-limpiadora-empacadora ... dora; and in our car we can have a lavasecaguardalimpia ... parabrisas.

In prefixation, too, it is impossible to come across cases which are clearly recursive. «Forms such as re-remake, meta-metatheory, and hemidemisemiquaver can be found even if they are rarely listed in the dictionaries» (Bauer 67). In the same line, Halle writes: «anti-missile missile, anti-anti-missile missile missile, and so on, an infinite series of words, each with a determinate meaning different from that of all the others» (Di Sciullo and Williams 7).

The recursive process carried out to its limits may produce grammatical structures but they are unacceptable. The native speaker, on the other hand, will never form words like those spontaneously, because intuitively he knows the limits which constrain their acceptability. 
Word formation rules allow the combination, in a fixed order, of words and affixes and affixes and words to form new derived and compound lexical units. They operate on words and affixes contained in the dictionary, and on new lexical formations produced by previous operations of the morphological rules. Each rule contains a series of conditions which determine the bases on which they operate and a series of constraints and filters which restrict their productive power. Simplifying it considerably we can reduce word formation rules to three; they can be formulated in the following way:

1. (prefix - (w)) $\rightarrow$ Derived word: inaccurate, reopen

2. $((w)$ - suffix $) \rightarrow$ Derived word: industrial, wordless

3. $((\mathrm{w})-(\mathrm{w})) \rightarrow$ Compound word: headache, apple tree

So formulated the three rules are not very useful. Their generative capacity is too extensive, and many of the generated words are unacceptable to native speakers, therefore, a series of conditions and constraints are necessary which restrict their generating capacity. It is obvious that the ideal native speaker, who only produces well-formed words which are acceptable to other speakers of the language, must have incorporated in his internalized lexical component the corresponding constraints.

These rules only operate on bases, words, which correspond to the open class categories, namely, nouns, adjectives, verbs and adverbs; they do not necessarily operate on a whole lexical category, but rather on word groups which are phonetically, syntactically or semantically similar; each rule operates only once on each base, but they can also operate on previously formed words to build units as complex as the following ones: civil $+i z+$ ation $+a l$, industri $+a l+i z+$ ation. It seems, then, that for a morphological rule to be useful it must contain the following information, for example:

$$
\left((w)_{x} \text { affix }\right)_{x} \rightarrow(w)_{x}
$$

$(\mathrm{f} \alpha) \quad(\mathrm{f} \beta) \quad(\mathrm{f} \gamma)$

which can be paraphrased in the following way: a rule of word formation which adds an affix of the category $X$ with the syntactic-semantic features $\beta$ to a word or root $W$ of category $\mathrm{X}$ with the syntactic-semantic features $\alpha$ generates a new lexical unit $\mathrm{W}$ of category $\mathrm{X}$ with the syntactic-semantic features $\gamma$, for example: nadador, goleador, esquiador, etc.

$$
\begin{aligned}
& \left((\text { trabaja })_{\mathrm{V}} \text { dor }\right) \rightarrow(\mathrm{W})_{\mathrm{N}} \\
& \text { (action) (nlzer) (agent) } \\
& (+ \text { transit) }
\end{aligned}
$$

The English rule operates in the same way and it is as productive as the Spanish one:

$$
\begin{aligned}
& \left((\text { play })_{V} \quad \text { er }\right)_{\mathrm{N}} \rightarrow(\mathrm{W})_{\mathrm{N}}: \text { swimmer, skier, dancer, etc. } \\
& \text { (action) (nlzer) (agent) } \\
& ( \pm \text { transit) }
\end{aligned}
$$


The most productive English deverbal compounds are those produced on a derived word as the determinatum and a primitive one as the determinant; the determinatum is always the theme or patient of the determinant, which is deverbal; their semantic content is that of activity or a job: bookkeeping, brainwashing, bullfighting, dressmaking or that of an agent or a person who practises that job or activity: bookeeper, brainhunter, bookseller, goalkeeper.

Now let us make some brief remarks on meaning. The study of the meaning of the processes of word formation is the weakest part of the morphological subcomponent, but it must be admitted that it has a very important role in the theory. Many of the restrictions on the application of word formation rules are semantic in nature. More research is necessary, however, before we can incorporate meaning into a morphological theory satisfactorily.

Words are polysemic by nature. But word formation rules do not necessarily operate with all meanings. Popular in Spanish, for example, has basically two meanings:

- which is of or for the general public: el voto popular, costumbres populares

- generally admired by great numbers of people: un cantante popular, un político popular

But the prefix in-may be added only to the word with the second meaning to express the opposite: un politico impopular, but *música impopular.

The meaning of complex and compound words is componential only when the structure is transparent to the speaker, when they are the result of the application of a word formation rule which is currently productive. Once formed, words may take on unpredictable meanings, which cannot be deduced from the meanings of their component parts, as for example: Spanish readmitir is «admitir de nuevo;» re- is a productive prefix when it has the meaning «again,» as in reutilizar, reinsertar, rehacer, etc. It is not in the following words: reanimar, reanudar, rebajar, revolver. But even in tranparent words there is always a meaning which is proper to the compound; shoemaking in English is not only the action of making shoes, but the activity or job which consists in making shoes.

Not all possible words are acceptable, however, in a particular speech community. There are rules, filters, which exclude from the language some of the new words which the speakers can generate; one of them is blocking. This filter blocks the operation of the rules when there exists an unmotivated lexical unit with the same meaning as the possible one. The generated word is not acceptable, for example: on the pattern represented by luchar - luchador in Spanish we may coin robar - *robador, charlar *charlador, barrer - *barredor, asesinar - *asesinador but the starred words are not acceptable because they are blocked by ladrón, charlatán, barrendero y asesino.

In English the suffix -ery is added to some names of goods to indicate the shops where they are sold. It is added to jewels to form jewelery a shop of jewels, to spices to form spicery, a spices shop, etc., and following this pattern the speaker may form * milkery, a milk shop, but this is blocked by dairy a long existing word in the language. Among the agent names which indicate the persons who do a job or a profession there exist in English play - player, dance - dancer, ski - skier, and following the same pattern the speaker may form steal - *stealer, but this is blocked by thief. 
Following these general principles of autoregulation of language, we are carried out to assume that when two suffixes with the same meaning, action or effect of, are attached to a base, one of the words should be lexicalized with a specific meaning, and this is what happens very often, for example: in Spanish hinchar - hinchazón hinchamiento, encantar - encantación - encantamiento. But this is not always so. There are some cases in which both derivations have identical meaning and the two are acceptable: convencer - convicción - convencimiento, abolir - abolición - abolimiento (Bustos 16).

\section{Morphology and the Learning of an Added Language}

Syntax contains the rules which allow us to combine words to form more complex units, phrases and sentences. The main thing we need in order to be able to speak are words, the acoustic or written images of our concepts.

Learning vocabulary is a very important part of learning English. If you make a grammatical mistake it may be «wrong» but very often people will understand you anyway. But if you don't know the exact word that you need, it is very frustrating for you, and the person you are talking to. Good English means having a big vocabulary! (Flower 5)

Words are stored in our memory and form a sort of dictionary. We do not know the characteristics of this internal dictionary, but we assume they must be similar to those of any reference dictionary. Words will be accompanied by the corresponding syntactic, phonological and semantic information which facilitates their incorporation in larger linguistic units without violating the rules of the linguistic system. It will contain the information which cannot be deduced from their form or from other more general principles, only idiosyncratic information, i.e. «It contains objects of no single specifiable type (words, VPs, morphemes, perhaps intonation patterns, and so on) and those objects that it does contain are there because they fail to conform to interesting laws. The lexicon is like a prison-it contains only the lawless, and the only thing that its inmates have in common is lawlessness» (Di Sciullo and Williams 3).

We assume anyway that the lexical entries in the dictionary have some sort of organization among them and the order in which they are arranged is not so anarchical as one might think. This conclusion is drawn after noticing the great accuracy and rapidity with which words are called for, which induces us to believe that only elements arranged in some specific way, either semantically or formally or both, will allow this. It is easier to find the things stored following some systematic principle than those amassed unorderly.

Those words which have a structure syntactically and semantically transparent need not be stored in this dictionary. Those regularities reflect the working of the system as a coherent non arbitrary mechanism and originate in the morphological subcomponent of the language.

Everything said so far leads us to draw out some conclusions which we can apply to the learning of a second language. To know a word is to know how articulate correctly the group of sounds which constitute it, to know the image that these sounds 
together call for, to know the rules of word derivation and word composition which operate on it, and to know the contexts in which it can be inserted. If we have concepts but we do not have the words which represent them acoustically and in writing it is as if we did not have them. The lack of lexical items when we need them makes a speaker's communication painful even for himself.

In an inquiry carried out in the Escuela Oficial de Idiomas de Barcelona among students of English we posed them questions on the linguistic aspects that they considered more important in order to reach their goal of speaking the language fluently. One question was «Are you capable of expressing yourself satisfactorily? What do you think you lack?» The age of the students ranged from 17 to 44 . Most of them were clerks and secretaries; there were also some primary school teachers, some nurses, and a few university students. From the 25 answers we collected we obtain the following percentage:

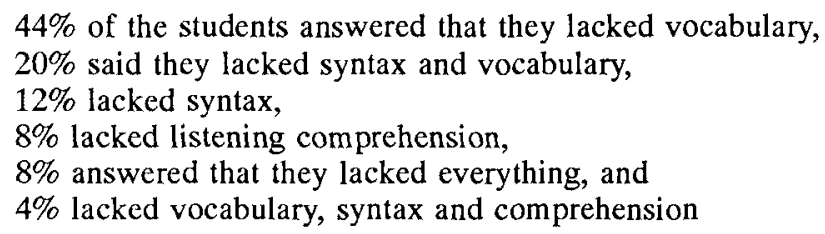

Even though the sample is too small, its indicative value is important. Most of our students answered that their main problem was the lack of vocabulary. This is very important when we compare it with other related studies. P. M. Meara reports on a considerable number of errors in Utrecht University which showed that lexical errors outnumbered grammatical errors by three or four to one. And R. L. Politzer (253-61) says that native speakers of German identified lexical errors of students of other languages as the most serious and disruptive in communication.

The children who learn an added language have to confront a series of data from the environment and abstract a series of general principles on how to form, pronounce, and interpret sentences and each of their constituents. When a two-year-old child surprises us with expressions such as goed, comed, buyed, thinked, etc. he/she is showing us that he/she has already acquired the rule of the English regular past tense. But as he/she ignores its restrictions he/she produces unacceptable forms instead of the acceptable irregular ones, went, came, bought, thought.

In 1972 this author collected material for a paper on psycholinguistics during a stay at Georgetown University. In the language recordings he made of Patrick, 23 months old at that time, there appear the following words:

$$
\begin{aligned}
& \text { /du:'daion/ - screwdriver } \\
& \text { /'æpl di/ - apple juice } \\
& \text { /‘den tr } \wedge \text { k - dump-truck }
\end{aligned}
$$

It is obvious that the boy acquired these compounds not because he had reached some sort of generalization of the morphological rules, but because he had heard them associated with some objects which were familiar to him. In the literature of word formation we find the testimony of parents who assert they have heard their children 
coin new compound words using productive patterns of the language. R. B. Lees (177) says that his four-year-old daughter, who did not know the word stretcher, coined carry-bed to name it following an English standard pattern of word formation as the one represented by showroom, «a room to show something in it.» $\mathrm{K}$. Croft relates that his three children aged nine, seven and three, on one occasion produced the compound words climbing tree and rolling ball. He states he understood the references perfectly although he had never heard them before. They follow the pattern of drinking water «water for drinking;» on another occasion, his three-year-old daughter coined the compound spanking ruler to refer to the instrument her father used to punish his students; it follows the pattern of curling iron, «an iron to curl hair» 71). And L. R. Gleitman mentions the fact that her two-year-old son called the map they were using on a trip a vacation paper following productive models in the language (101). It seems, then, that children very early incorporate the rules of word formation to their grammatical competence.

Derwing, however, notes that his daughter «was nearly four years old before she noted (to her delighted surprise) that even oranges and orange juice had anything in common» (quoted in Bauer 44).

We must conclude, then, that native children learn complex and compound words first as unanalyzable wholes. But quite early they realise that some nouns follow patterns in the language. When a ten-year-old Spanish boy says that the fathers of the aircraft were «fabricadores de bicicletas» it is obvious he has acquired the productive rule for the formation of agent nouns, i.e., you add the suffix -dor to the theme vowel of the verbs in -ar, following patterns such as jugar - jugador, comprar - comprador. Only later will he learn that some of these verbs add other suffixes to indicate the agent: fabricar - *fabricador - fabricante.

To learn an added language means to acquire some knowledge of the language system which allows the learner to express himself with the greatest fluency possible. During the last two decades or so linguists have been looking for evidence to test the philosophical bases of the linguistic thought brought about as a consequence of Chomsky's linguistic revolution. Nowadays psycholinguists coincide in stating that added language acquisition is favoured by the learner's interaction in the added language creating his own grammatical constructions and building hypotheses on their use.

Something very important for the added language teacher is the contribution of the learner's native language to the learning of the added language. Language theoreticians have not reached a general consensus about it yet. We will make some remarks regarding the acquisition of words and the rules of word formation.

We assume that learning takes place when we associate new concepts and ideas with others acquired before. In the added language learning situation the influence of the first language is noticeable in those structures whose similarity in the native and in the target language is patent. An example is the influence of the native language lexicon on that of the added language during the learning process. False friends are words of the added language that in spelling, sound, or both look very familiar to us and we attribute to them the meaning those words have in our language. This is the case of the words below:

cage when it is translated as caja instead of jaula

library when it is translated as libreria instead of biblioteca 
casualty when it is translated as casualidad instead of victima advice when it is translated as aviso instead of consejo

Productive word formation rules of the native language may also influence those of the added language, especially those whose similarity with those of the native language is obvious. This is the case of the examples below taken from the examination papers of students who were writing their University Entrance Examinations (PAAU in Spanish):

a. Television has unificated those cultures

b. They are all trying to conservate their traditions

c. The whole tribe was preocupated about it

d. . . and I always imaginated I was a primitive man (Domínguez 67-78)

We have three possible explanations of those forms, but only two of them seem to be the most probable. First, the students know forms such as contemplate, moderate, accumulate, etc. and build their own verbal forms by a process of analogy. Second, the students have several times come across the English nouns in -ation, very similar to their Spanish homonyms in -acción, as we can see below:

unificación - unification

conservación - conservation

preocupación - preocupation

imaginación - imagination

We notice their formal and phonetic similarity. In Spanish the nominalizer -accion is a productive suffix which is added to verbs ending in -ar; by a process of backformation Spanish learners may derive English verbs in -ate to translaie the Spanish verbs in -ar, i.e.:

moderate - moderar

accumulate - acumular

contemplate - contemplar

and they conclude that all Spanish verbs in -ar have an English equivalent in -ate. The first hypothesis is a case of overgeneralization of the rules of the added language; the last two are cases of crosslinguistic influence, and in my view they present a more reasonable explanation of the phenomenon.

\section{Conclusions}

The lexical component is a very important part of the grammar of a language. The morphological rules, which are a part of it, provide the speaker with the means to form new lexical units, and to accept or discard the newly formed words he comes across as well or wrongly formed. 
As for the productivity of the word formation rules, we have seen these have recursive devices like the syntactic ones, which allow the speaker to generate an infinite number of derived and compound words. But like syntactic rules, morphological rules need be specified by conditions and constraints in order to avoid overgeneration.

In morphology the bases, but also the affixes and units resulting from the operation of the rules, must be specified with the corresponding category and the syntacticsemantic selectional features.

Meaning is a basic point to take into account in word formation, but we need more principle systematic descriptions in order to use it explanatorily.

Learning morphology is similar to the learning of the other grammatical components. First, we have to internalize lexical entries, later the contact with language makes the learner understand that some words have transparent internal structure generated by the rules of the language, which allow the speakers to coin their own derived and compound words.

As for the learning of the added language, the rules of the native and added languages which are similar cause the learner to apply the rules of his native language to produce and interpret morphological structures in the added language.

\section{Works Cited}

Bauer, L. English Word-Formation. Cambridge: Cambridge UP, 1983.

Bustos Gisbert, E. La composición nominal en español. Salamanca: U de Salamanca, 1986.

Chomsky, N. Aspects of the Theory of Syntax. Cambridge, Mass.: The MIT P, 1965. . «Remarks on Nominalization.» Readings in English Transformational Grammar. Eds.

Jacobs and Rosenbaum. Waltham, Mass.: Ginn, 1970. 184-221.

Croft, K. English Noun Compounds. Experimental edition. Washington, D.C.: Georgetown U, 1964.

Di Sciullo, A. M. and E. Williams. On the Definition of Word. Cambridge, Mass.: The MIT P, 1987.

Domínguez, J. A. «Problems of Spanish Students Learning English: The Verb Phrase.» Anuari d'Anglès 13 (1990): 67-68.

Flower, J. Building your Vocabulary. L.T.P., 1989.

Gleitman, L. R. and N. Gleitman. Phrase and Paraphrase. New York: Norton, 1970.

Lees, R. B. The Grammar of English Nominalizations. The Hague: Mouton, 1963.

Meara, P. M. «Study of Lexis in Interlanguage.» Paper presented at the International Language Seminar in Honour of S. P. Corder. U of Edinburgh, 1984.

Politzer, R. L. «Errors of English Speakers of German Received and Evaluated by German Natives.» Modern Language Journal 62 (1978): 253-61.

Radford, A. Transformational Syntax. Cambridge: Cambridge UP, 1981.

Scalise, S. Generative Morphology. Dordrecht: Foris, 1984. 